\title{
Brief communication: Virtual reconstruction of the Early Pleistocene mandible ATD6-96 from Gran Dolina-TD6-2 (Sierra de Atapuerca, Spain)
}

José María Bermúdez de Castro 1,2*

Laura Martín-Francés ${ }^{1}$

Mario Modesto-Mata ${ }^{1,3}$

Marina Martínez de Pinillos ${ }^{1}$

María Martinón-Torres 2,4

Cecilia García-Campos ${ }^{1}$

José Miguel Carretero ${ }^{4}$

1. Centro Nacional de Investigación sobre la Evolución Humana (CENIEH), Burgos, Spain.

2. University College London (UCL) Anthropology, 14 Taviton Street, London WC1H 0BW, UK

3. Equipo Primeros Pobladores de Extremadura (EPPEX), Casa de la Cultura Rodríguez Moñino, Av. Cervantes s/n, 10003 Cáceres, Spain.

4. Departamento de Ciencias Históricas y Geografía. Universidad de Burgos, Hospital del Rey s/n. 09001 Burgos, Spain.

№ pages: 17

№ tables: 4

№ figures: 5

Abbreviated title: Virtual reconstruction of ATD6-96 mandible

KEY WORDS mandible, virtual reconstruction, Homo antecessor, Sierra de Atapuerca

Corresponding author:

José María Bermúdez de Castro

Address: Centro Nacional de Investigación sobre la Evolución Humana (CENIEH), Burgos. Paseo de la Sierra de Atapuerca 3, 09002 Burgos, Spain.

Telephone number: 34947040800

Fax number: 34947040810

Email: josemaria.bermudezdecastro@cenieh.es

Grant sponsor: Dirección General de Investigación of the Spanish Ministerio de Educación y Ciencia (MEC); Grant numbers: CGL2009-12703-C03-01 and 02. Grant 
sponsor: Junta de Castilla y León; Grant numbers: BOCYL-D-30122013-33 and BOCYLD-20122012-38. Grant sponsors: Consejería de Cultura y Turismo of the Junta de Castilla y León; Fundación Atapuerca; Leakey Foundation.

\section{ABSTRACT}

\section{Objectives}

In this report we present a further study of the late Early Pleistocene ATD6-96 human mandible, recovered from the TD6-2 level of the Gran Dolina cave site (Sierra de Atapuerca, northern Spain) and attributed to Homo antecessor.

\section{Methods}

ATD6-96 consists of a left half of a gracile mandible of an adult individual with the premolars and molars in place that is broken at the level of the lateral incisor-canine septum. The present analysis is based on a virtual reconstruction of the whole mandible by means of computed tomography (CT). We have reconstructed the symphysis using information from a modern human sample, as well as from a wide sample composed of several Homo specimens.

\section{Results}

This research has allowed us to record new variables with taxonomic and phylogenetic interest. We have estimated the length/width index of the alveolar arcade, as well as the percentage of the arcade length with regard to the total length. The latter confirms that ATD6-96 shares with all African and Asian Homo species a primitive structural pattern, as it was established in previous studies. In constrast, the length/width index of the alveolar arcade in the $H$. antecessor specimen is close to the mean values of Neandertals and the Atapuerca-Sima de los Huesos hominins.

\section{Conclusions}

H. antecessor is derived regarding the shape of the mandibular alveolar arcade within the genus Homo and points to an early divergence from contemporaneous African populations. Our results also ratify the affinities of $H$. antecessor with Neanderthals, although the precise relationship with this lineage needs further research. 


\section{INTRODUCTION}

Three-dimensional (3D) virtual imaging has become an essential tool in palaeoanthropological studies. It is common that fossils are recovered from the sites with some preservation damage such as post-depositional breakages, distortion due to sediment pressure or some degree of incompleteness. Thanks to the aid of 3D virtual imaging techniques we can now reconstruct damaged specimens and obtain new type of data on old and new fossil findings (e.g., Ponce de León, and Zollikofer, 1999; Manzi et al., 2001; Sémal et al., 2005; Zollikofer et al., 2005; Sylvester et al., 2005; Guipert et al., 2007; Mafart et al., 2007; Gunz et al., 2009; Berge and Goularas, 2010; Bermúdez de Castro el al., 2010; Vialet et al., 2010; Spoor et al., 2015).

In this report we aim to present new variables of taxonomic interest from the mandible ATD6-96, recovered in 2003 from the TD6-2 level of the Gran Dolina cave in Sierra de Atapuerca, northern Spain. Although this mandible has been already the subject of previous studies (Carbonell et al., 2005; Bermúdez de Castro et al., 2014) there were some variables that could not be assessed due to its degree of incompleteness. In this study we performed a virtual reconstruction of the missing parts of the mandible by means of computed tomography (CT) and we obtained new information that is relevant, not only about this specimen in particular, but also about the evolutionary meaning of the Gran Dolina-TD6 hominin assemblage. These hominins represent one of the oldest European humans (Homo antecessor, Bermúdez de Castro et al., 1997) and display a particular combination of cranial and postcranial features that may be crucial for understanding the first settlement of Europe.

\section{MATERIALS}

\section{The TD6 level}

The Gran Dolina cave site (TD) fills up a large cavity about $27 \mathrm{~m}$ deep and with a maximum width of $17 \mathrm{~m}$. The stratigraphic section of the site was cut and exposed 
by the construction of a railway trench. Gil and Hoyos (1987) divided this section from bottom to top into eleven levels: TD1 to TD11. However, the stratigraphy of the Gran Dolina site is under continuous refinement. There is a vertical cut of the section in progress (e.g. Bermúdez de Castro et al., 2008). In addition, a wide pit about 10 meters deep, excavated below the present level of the ancient railway, is currently under study. Parés and Pérez-González $(1995,1999)$ observed a polarity reversal between TD7 and T8, interpreted as the Matuyama/Brunhes boundary, meaning that levels TD8-TD11 were deposited during the Middle Pleistocene, whereas levels TD7TD1 were attributed to the Early Pleistocene. The combination of paleomagnetic data and US-ESR ages suggests an age range between 0.78 and $0.86 \mathrm{Ma}$ (million years ago) for TD6-2 (Falguères et al., 1999). Thermoluminiscence (TL) ages on samples taken one meter below the Brunhes/Matuyama boundary ( $0.78 \mathrm{Ma}$ ) give an age of $0.96 \pm 0.12$ Ma for TD6 (Berger et al., 2008), which may correspond to MIS 25. The last systematic dating of the Gran Dolina sequence has been made by Moreno (2011) using the ESR dating method on optically bleached quartz. Moreno analysed six samples for TD6 and TD7, obtaining an age range of 0.80-0.88 Ma for these levels, which is consistent with the biostratigraphic and paleomagnetic analyses and suggest that the TD6 human assemblage was likely deposited during the MIS 21.

\section{The mandible ATD6-96}

The specimen ATD6-96 was recovered in 2003 during the excavation of a small area of the TD6-2 level, near the test pit digged during the 1994-1997 field seasons. ATD696 is a left half of a gracile mandible of an adult individual with the premolars and molars in place. ATD6-96 presents a peri-mortem fracture at the level of the lateral incisor-canine septum and from this point the whole right side is missing. It also presents some minor cracks between the corpus and the ramus, at the region of the gonial angle and the neck of condyle that have not altered the original morphology. A noticeable elevation at the basal border suggests the birth of the genial apophysis. The third molar (M3) is fully erupted and shows a minimal wear facet at the mesial 
marginal ridge. During the restoration process of the ATD6-96 specimen (López-Polín et al., 2008), the corpus and ramus were separated, and the roots of the M3 could be observed directly. These roots are at stage RC of tooth formation (Moorrees et al. 1963). Given the small size of ATD6-96 (Figure 1) we consider that this specimen probably belonged to a female individual (Carbonell et al., 2005).

[Figure 1]

\section{METHODS}

The methodology applied for the study of ATD6-96 includes the virtual reconstruction of the mandible by mirroring the preserved portions and by estimating the width of the missing symphysis. Once the whole mandible was virtually reconstructed we recorded some variables with taxonomic interest related with the shape and measurements of the mandibular arcade.

The specimen ATD6-96 was scanned with a Tomographic system (Tomograph YXILON Compact Yxlon International, X-Ray Gmbh) housed at the University of Burgos, using the following settings: voltage $130 \mathrm{kV}$, amperage $4 \mathrm{~mA}$ and resultant voxel size of $0.109 \mathrm{~mm} \times 0.109 \mathrm{~mm} \times 0.20 \mathrm{~mm}$. The resulting images were imported into Amira (Visage Imaging) software to obtain the 3D volume of the mandibular left side. Following, a second reconstruction was performed by mirror-imagining the original stack of images (left hemimandible) to obtain the right hemimandible and create the 3D volume. Moreover, a cast of the right and left sides of ATD6-69 was produced (Scanner 3D Nextengine housed at the University of Burgos) to assist in the digital reconstruction.

As the canine alveolus is not complete due to a post-depositional breakage it was necessary to mirror the remaining half. The reconstructed 3D volume was then aligned and placed resulting in an entire alveolar rim. The same process was performed on the right side.

Next, both the left and right hemi-mandibles were rotated on the " $x, y$ and z" 
planes until the anatomical position was reached, that is, that the wear plane of the buccal cusps of the P4 and M1 is positioned approximately in the same plane and perpendicular to the vertical axis.

Once the two hemimandibles are orientated we still have to spatially align one respect to the other. For this purpose it is necessary to reconstruct the symphyseal region. To achieve this goal we defined two landmarks: 1 - the middle point of the internal side (IS) of the interdental septum between the permanent canine (C) and the permanent lateral incisor (I2), 2- the middle point of the external side (ES) of the interdental septum between the C and I2.

Then, we obtain the variables IS-IS and ES-ES with a Limit @ digital caliper. ISIS is defined as the distance between the middle innermost point of the interdental septum between the $\mathrm{C}$ and the $\mathrm{I} 2$ on the right side, and the same point on the left side. ES-ES is defined as the distance between the middle outermost point of the interdental septum between the $\mathrm{C}$ and the $\mathrm{I} 2$, on the right side, and the same point on the left side, respectively. These points are easy to determine and their identification is straightforward. The most important consideration concerning these landmarks is that they are not related to the morphology of the symphysis. The morphology of this part of the mandible is highly variable in hominins and highly derived in modern humans. Consequently we need to reconstruct the missing part of ATD6-96 employing only size information. The IS-IS and ES-ES variables are a reference to obtain the width of the symphysis, and they are independent of the morphological features (e.g., mental trigone, mental fossae, etc.), of this part of the mandible.

In order to confirm the reliability of these landmarks, the IS-IS and ES-ES variables were independently obtained by two of us (MM-M and CG-C) in the same modern human mandibular sample. In both cases the variables followed a normal distribution (Kolmogorov Smirnov test; $p>0.05$ ). Homogeneity of the variances is also accomplished (Levene test, $\mathrm{p}>95 \%$ ). The ANOVA analysis gives a $\mathrm{p}$-value of 0.607 for the ES-ES variable and a p-value of 0.502 for the IS-IS variable. In summary, no significant differences ( $95 \%$ of signification level) were observed between the 
measurements obtained by MM-M and CG-C. Using the formula ([(m1-m2)/m2]x 100), where $\mathrm{m} 1$ and $\mathrm{m} 2$ are the measurements obtained by each observer, the interobserver average error was 3.0\% for the IS-IS variable and $4.4 \%$ for the ES-ES variable.

Furthermore, in order to analyse the goodness of these measurements we carried out a linear regression analysis of these two variables (IS-IS and ES-ES) measured in a modern human sample $(\mathrm{N}=30)$. The analysis was performed with $\mathrm{R}$ statistical language and its graphical user interface $\mathrm{R}$ Commander. The distribution of the data fits a linear regression ( $\mathrm{p}$-value $=6.16 \times 10^{-6}, \mathrm{R}^{2}=0.52$ ). The equation and their confidence intervals (95\%) are:

IS-IS $=4,39+0,61 \times$ ES-ES

95\% Lower IS-IS $=-0,05+0,39 \times$ ES-ES

95\% Upper IS-IS = 8,84 + 0,83 x ES-ES

Given a mean value of 19.8 for the ES-ES (independent variable), the $95 \%$ confidence interval for IS-IS is 16.1-16.8 (mean value: 16.5)

The values indicate that it exists a good correlation between these two landmarks/anatomical features, so we can confidently use them to "anchor" one hemimandible with regard to the other and to estimate the width of the symphysis and the spatial relationship of the hemimandibles.

In order to estimate the width of the symphyseal region in ATD6-96 we have followed different approaches. The first approach is based on the symphyseal width of a modern sample. We employed a sample of 30 modern human mandibles of unknown sex from the San José cemetery of Burgos, housed at the Laboratory of Human Evolution (University of Burgos). Using the mean values, as well as the $95 \%$ confidence interval of the mean vales of the modern population (see above) could be a reasonable approach to our reconstruction, since ATD6-96 is a small specimen. However, we realize that by using a modern population (or any other hominin 
population) we fall into circular reasoning. Ideally, we would need a large number of mandibles from the same Early Pleistocene H. antecessor population to have a high interval of confidence in the reconstruction. For this reason, in a second approach we recorded the IS-IS and ES-ES variables in a selected sample of mandibles belonging to different Homo paleodemes (species). The specimens studied were originals (Dmanisi, Tighenif, Arago, and Atapuerca-Sima de los Huesos) and first generation casts. Four of these specimens (D211, D2735, KNM ER-820, and KNM-WT 15000) have a U-shaped alveolar arcade. Each reconstruction requires a correct orientation of the mandibles and it is a manual time-consuming task. As expected, using the measurements of some large hominins specimens in the reconstruction resulted in symphysis with a large width.

Finally, once the mandible has been reconstructed we recorded a series of mandibular measurements with taxonomic value to assess the phylogenetic affinity of this specimen in relation to others of the fossil record (see Table 3 of this article and Rosas and Bermúdez de Castro, 1998; Gabounia et al. 2002). Following Rosas and Bermúdez de Castro (1998) we obtained the width (defined as the M3-M3 distance) and the length (the distance between the infradentale (ID) and the distal surface of the M3) of the mandible. The ID is taken at the middle point of the ES-ES distance. With these measurements we obtained the length/width index. Moreover, we also calculated the total length of the mandible (L11) and the total length of the alveolar arcade (L7) (Gabounia et al., 2002). The maximum length of the alveolar arcade of ATD6-96 virtual reconstruction was taken with the specimen placed in the same anatomical position as the rest of the mandibles, that is, with the wear plane of the P4 and the M1 positioned in the same plane and perpendicular to the vertical axis. The maximum length is the perpendicular between the ID and the line joining the more distal points of the right and left condyles. The L7/L11 represents the percentage of the alveolar arcade with regard to the total length of the mandible.

\section{RESULTS}


Table 1 shows the descriptive statistics for the IS-IS and ES-ES measurements and for the IS-IS/ES-ES relationship of the modern human sample from the San José cemetery. In Table 2 we give the IS-IS and ES-ES measurements obtained in the Homo sample. It is interesting to note that the relationship between IS-IS/ES-ES in this sample is between the range of variation of the 30 human modern specimens from the San José cemetery (Table 1), so it seems a relatively constant index regardless taxonomic assignment of the specimen employed as a reference for the reconstruction. Therefore, although we could have used a larger Homo sample, it seems reasonable to expect that the results would be the same.

[Table 1 and Table 2]

Using the mean values of the IS-IS and ES-ES measurements obtained in the modern human sample and in some Homo specimens, we obtained a certain number of virtual reconstructions for the ATD6-96 mandible. This way our reconstructions is not taxonomically biased a priori and we break a possible circular reasoning.

[Figure 2]

Using the mean values of the modern human sample (Table 2) we obtain the reconstruction showed in figure 2, in which the length (ID-M3) is 62.5 and the width (M3-M3) is 73.6. The length/width index is 84.9. When we make the reconstruction using the IS-IS and ES-ES values obtained in different Homo specimens we get similar values for the length (range: 63.2 - 64.3) and a range between 71.1 and 81.2 for the width (Table 3 and Figure 3).

\section{[Figure 3]}

In all cases, including the 95\% confidence interval for the modern sample, we have obtained a length/width index below 90, with a range of 79.2 to 89.3 (Table 3 and Fig. 4). In general, the larger is the Homo specimen used in the reconstruction the lower the length/width index. Given the small size of ATD6-96, we expect that the most appropriate values are the IS-IS and ES-ES obtained in the modern human sample 
(mean values). These values give a length/width index of 84.9.

[Table 3]

The length/width index obtained in the modern human sample is similar to that of Neandertals and the Atapuerca-Sima de los Huesos hominins, and lower than that obtained in other European and Asian Middle Pleistocene hominins and H. sapiens (see Fig. 4 and Table 3 of Rosas and Bermúdez de Castro, 1998). A value of 84.9 means that the alveolar arcade of ADT6-96 was parabolic and therefore, derived regarding the Homo U-shaped primitive condition. In order to further test how reliable is this shape, we explore how the two hemimandibles should rotate in order to obtain a Ushaped arcade. If we take as a fixed value the mean of the IS-IS distance obtained in a modern sample, the ES-ES distance should increase up to $24.0 \mathrm{~mm}$ to get a U-shape. As we can see en Table 2, this ES-ES value is similar to that of the larger specimens of the Homo sample (e.g., Tighenif 2 and 3, Mauer, etc.), so it does not look reasonable for a mandible as small as ATD6-96. In contrast, if we rotate the hemimandibles to obtain a parabolic arcade using the same IS-IS distance, the ES-ES distance decreases to more reasonable values, between $20.0-22.0 \mathrm{~mm}$ or even less.

Using all the reconstructions obtained using the modern sample, as well as the different hominins, we have estimated the L7 and L11 variables. In average, the length of the alveolar arcade represents about the $54 \%$ of the total length of the mandible (range 53.5 - 54.7), aligning ATD6-96 with specimens like Bañolas or Montmaurin, and clearly surpassing the values of Neandertals, Mauer, and Arago 2 (Table 4).

[Figure 5 and Table 4]

\section{DISCUSSION}

In this study we performed a virtual reconstruction of the Early Pleistocene mandible ATD6-96 recovered from the TD6-2 level of the Gran Dolina site, in Sierra de Atapuerca. This reconstruction allowed us to obtain some measurements, which are 
useful for estimating some indices with taxonomic utility signal.

The shape of the alveolar arcade is related to the overall architecture of the skull. In a study of the Dmanisi mandible D211, Rosas and Bermúdez de Castro (1998) obtained a value of 110.2 for the length/width index of the alveolar arcade of this specimen. This value is similar to that recorded in some A. afarensis specimens, $\mathrm{OH} \mathrm{13,}$ KNM-ER 1805, KNM-ER 992, KNM-BK 8518, KNM-BK 67, and one specimen from Zhoukoudian (ZHD H1). Other Asian H. erectus, like Lantian and ZHD G1 show index values close to 100.0. Similarly, we estimate that a value above 100 for this index could be obtained for the recent reconstruction of OH 7 (Spoor et al., 2015). Furthermore, whereas it is not possible to obtain this index in the immature individual KNM-WT 15000, this specimen exhibits a clear U-shaped mandibular dental arcade. In other words, mandibles with an index about 100 or above this value display a narrow and broadly U-shaped arcade, and this can be considered as the primitive condition for the Homo clade. In contrast, the Middle and Early Pleistocene mandibles show values of the index less that 100 (Rosas and Bermúdez de Castro, 1998), displaying a parabolic alveolar arcade and a much wider M3 bi-molar width than the archaic Homo mandibles. In ATD6-96 this variable would be slightly above 70.0 like in the majority of the European Pleistocene specimens. The estimated index of the alveolar arcade in ATD6-96 is close to the mean values of Neandertals and the Atapuerca-SH hominins. Therefore, we can conclude that $H$. antecessor is derived for the Homo clade regarding the shape of the mandibular alveolar arcade.

Concerning the total length of ATD6-96 it is interesting to note that this specimen is the smallest of the large sample studied by Gabounia et al. (2002) (Table 4 and Fig. 5). This could support the assignment of ATD6-96 to a female individual. Previous studies pointed out that ATD6-96 exhibits a primitive structural pattern shared with all African and Asian Homo species, defined by features such as the position of the mental foramen, the lateral prominence, and the mylohyoid line in relation to the alveolar margin at M3 level, as well as the relief of the pterygoid fossa or the intersection between the mandibular notch and the condyle (Carbonell et al., 2005). The percentage of the alveolar arcade obtained in our reconstruction can be 
also considered within this primitive Homo structural pattern. In fact, for this feature, ATD6-96 is placed with several African and Eurasian Early and Middle Pleistocene Homo specimens, between the high percentages obtained for Australopithecus and Paranthropus and the low percentages of the Neanderthals (see Figure 3 of Gabounia et al., 2002). In these hominins mid-facial prognathism is responsible for the relative short dental arcade with regard to the total length of the mandible. In contrast, ATD696 is derived concerning other features such as the oblique inclination of the retromolar area, the partial covering of the M3 by the ramus, or the absence of alveolar prominence (Carbonell et al., 2005).

Our results have provided an index of the alveolar arcade that is similar to the mean values obtained in Neandertals and the SH hominins. This result is not fully surprising, given that $H$. antecessor shares other features with Neandertals and the $\mathrm{SH}$ hominins (Arsuaga et al., 1999; Carretero et al., 1999; Gómez-Robles et al., 2007; Bermúdez de Castro et al., 2012). Furthermore, we also noticed a large medial pterygoid tubercle present in ATD6-96, a feature that is highly frequent in Neandertals (89\%) and the Atapuerca-Sima de los Huesos (SH) hominins (55\%) (Bermúdez de Castro et al., 2014).

As we concluded in previous studies, all these features cannot be considered as Neandertal autopomorphies, but traits which may have appeared much earlier than previously considered, in an Early Pleistocene hominin population. Considering these results and the fact that the mandibular body of the H. antecessor mandibles is low and narrow (Rosas and Bermúdez de Castro, 1999; Carbonell et al., 2005; Bermúdez de Castro et al., 2008) we consider that these hominins clearly diverged from other African Early Pleistocene hominins. In contrast, the TD6 hominins exhibits clear affinities with Pleistocene Eurasian hominins and show a particular and intriguing mosaic of features (Bermúdez de Castro et al., 2015).

\section{ACKNOWLEDGEMENTS}


The authors acknowledge all members of the Atapuerca Research Team for their dedication and effort. To Lucía López-Polin, from the IPHES Restoration and Conservation Department, for the cleaning of the specimen, and to Pilar Fernández Colón and Elena Lacasa Marquina, from the CENIEH Conservation and Restoration and Conservation Department, for their work with the conservation, and manipulation of the specimen. Special thanks are given to the Universidad de Burgos team (Rebeca García, Laura García, Yuliet Quintino y Amalia Pérez) for scanning the specimen ATD696 and for helping access to the skeletal collections under their care. We also acknowledge the Leakey Foundation through the personal support of Gordon Getty and Dub Crook to one of the authors (MM-T). LM-F is beneficiary of a Fundación Atapuerca Post-Doctoral Research Grant, whereas MM, MM-P and CG have PreDoctoral contracts of the Junta de Castilla y León.

\section{LITERATURE CITED}

Arsuaga JL, Martínez I, Lorenzo C, Gracia A, Muñoz A, Alonso O, Gallego J, 1999. The human cranial remains from Gran Dolina Lower Pleistocene site (Sierra de Atapuerca, Spain). J Hum Evol 37, 431-457.

Berge C, Goularas D, 2010. A new reconstruction of Sts 14 pelvis (Australopithecus africanus) from computed tomography and three-dimensional modeling techiniques. J Hum Evol 58: 262-272.

Berger GW, Pérez-González A, Carbonell E, Arsuaga JL, Bermúdez de Castro JM, Ku TL, 2008. Luminescence chronology of cave sediments at the Atapuerca paleoanthropological site, Spain. J Hum Evol 55: 300-311.

Bermúdez de Castro JM, Arsuaga JL, Carbonell E, Rosas A, Martínez I, Mosquera M, 1997. A hominid from the Lower Pleistocene of Atapuerca, Spain: possible ancestor to Neandertals and modern humans. Science 276:1392-1395.

Bermúdez de Castro JM, Rosas A, Nicolás ME, 1999. Dental remains from Atapuerca- 
TD6 (Gran Dolina site, Burgos, Spain). J Hum Evol 37: 523-566.

Bermúdez de Castro JM, Pérez-González A, Martinón-Torres M, Gómez-Robles A, Rosell J, Prado L, Sarmiento S, Carbonell E, 2008. A new Early Pleistocene hominin mandible from Atapuerca-TD6, Spain. J Hum Evol 55: 729-735.

Bermúdez de Castro JM, Martinón-Torres M, Gómez-Robles A, Prado L, Rosell J, Gómez-Polín L, Arsuaga JL, Carbonell E, 2010. New immature hominin fossil from European Lower Pleistocene shows the earliest evidence of a modern human dental development pattern. Proc, Natl Acad Sci, USA 107: 11739-11744.

Bermúdez de Castro JM, Carretero JM, García-González R, Rodríguez-Gracía L, Martinón-Torres M, Rosell J, Blasco R, Martín-Francés L, Modesto M, Carbonell E, 2012. Early Pleistocene human humeri from the Gran Dolina-TD6 site (Sierra de Atapuerca, Spain). Am J Phys Anthropol 147, 604-617.

Bermúdez de Castro JM, Quam T, Martinón-TorresM, Martínez I, Gracia-Téllez A, Arsuaga JL, Carbonell E, 2014. The medial pterygoid tubercle in the Atapuerca Early and Middle Pleistocene mandibles. Evolutionary implications. Am J Phys Anthropol 156: 102-109.

Bermúdez de Castro JM, Martinón-Torres M, Martín-Francés L, Modesto-Mata M, Martínez-de-Pinillos M, García C, Eudald Carbonell E, 2015. Homo antecessor. The state of the art eighteen years later. Quat Int, in press.

Carbonell E, Bermúdez de Castro JM, Arsuaga JL, Allue E, Bastir M, Benito A, Cáceres I, Canals T, Díez J., van der Made J, Mosquera M, Ollé ., Pérez- González A, Rodríguez J, Ródríguez XP, Rosas A, Rosell J, Sala R, Vallverdú J, Vergés JM 2005. An early Pleistocene hominin mandible from Atapuerca-TD6, Spain. Proc. Natl. Acad. Sci. USA 102: 5674-5678. 
Carretero JM, Lorenzo C, Arsuaga JL, 1999. Axial and apendicular skeleton of Homo antecesor. J Hum Evol 37, 459-499.

Falguères C, Bahain JJ, Yokoyama Y, Arsuaga JL, Bermúdez de Castro JM, Carbonell E, Bischoff J, Dolo JM 1999. Earliest humans in Europe: the age of TD6 Gran Dolina, Atapuerca, Spain. J Hum Evol 37: 343-352.

Gabounia L, de Lumley MA, Vekua A, Lordkipanidze D, de Lumley H, 2002. Découverte dún nouvel hominidé à Dmanissi (transcaucasie, Géorgie). C R Palevol 1: 243-253.

Gil E, Hoyos M, 1987. Contexto estratigráfico. In: Aguirre E, Carbonell E, Bermúdez de Castro JM, editors. El Hombre Fósil de Ibeas y el Pleistoceno de la Sierra de Atapuerca. Junta de Castilla y León, Valladolid. p 47-55.

Gómez-Robles A, Martinón-Torres M, Bermúdez de Castro JM, Margvelashvili A, Bastir M, Arsuaga JL, Pérez-Pérez A, Estebaranz F, Martínez LM, 2007. A geometric morphometric analysis of hominin upper first molar shape. J Hum Evol 53, 272-285.

Guipert G, Mafart B, Tuffreau A, Lumley MA, 2007. 3D reconstruction and study of a new late Middle Pleistocene Hominid: Biache-Saint-Vaast 2, Nord France. Am J Phys Anthropol Sppl 44: 121-122.

Gunz P, Mitteroeceker P, Naubauer, Weber GW, Bookstein FL, 2009. Principles for the virtual reconstruction of hominin crania. J Hum Evol 57: 48-62.

López-Polín L, Ollé A, Cáceres I, Carbonell E, Bermúdez de Castro JM 2008. Pleistocene human remains and conservation treatments: the case of a mandible from Atapuerca (Spain). J Hum Evol 54: 539-545.

Mafart B, Guipert G, Allinez-Philip C, Brau JJ, 2007. Virtual reconstitution and new paleopathological study of the Magdalenian skull of Rochereil. CR Palevol 6: 569-579. 
Manzi G, Bruner E, Caprasecca S, Gualdi G, Passarello P, 2001. CT-scanning and virtyal rteconstruction of the Saccopastore Neandertal crania. Riv Antropol 79: 61-72.

Moreno D, 2011. Datation par ESR de quartz optiquement blanchis (ESR-OB) de la région de Atapuerca (Burgos, Espagne). Application au site préhistorique de Gran Dolina (contexte karstique) et aux systèmes fluviatiles quaternaires de l'Arlanzón et l'Arlanza. Ph D. Dissertation. Universitat Rovira i Virgili, Tarragona, Spain and Muséum National d'Histoire Naturelle, (MNHN, París, France).

Moorrees CFA, Fanning EA, Hunt EE, 1963. Formation and resorption of three deciduous teeth in children. Am J. Phys Anthropol 21: 205-213.

Parés JM, Pérez-González A, 1995. Paleomagnetic age for hominid fossils at Atapuerca Archaeological site, Spain. Science 269: 830-832.

Parés JM, Pérez-González A. 1999. Magnetochronology and stratigraphy at Gran Dolina section, Atapuerca (Burgos, Spain). J Hum Evol 37: 325-342.

Ponce de León MS, Zollikofer CPE, 1999. New evidence from Le Moustier 1: computerassited reconstruction and morphometry of the skull. Anat Record 254: 474-489.

Rosas A, Bermúdez de Castro JM, 1998. On the taxonomic affinities of the Dmanisi mandible (Georgia). Am J Phys Anthropol 107: 145-162.

Rosas A, Bermúdez de Castro JM, 1999. The ATD6-5 mandibular specimen from Gran

Dolina (Atapuerca, Spain). Morphological study and phylogenetic implications. J Hum Evol 37, 567-590.

Sémal P, Toussaint M, Maureille B, Rougier H, Crevecoeur I, Balzeau A, Bouchneb L, Louryan S, de Clerck N, Rausin L, 2005. Numérisation des restes humains 
néandertaliens belges. Préservation patrimoniale et explotation scientifique. Notae Praehistoricae 25: 25:38.

Spoor F, Gunz P, Neaubauer S, Stelzer S, Scott N, Kwekason A, Dean MC, 2015.

Reconstructed Homo habilis type $\mathrm{OH} 7$ suggests deep-rooted species diversity in early Homo. Nature 519: 83-86.

Sylvester AD, Merkl BC, Mahfouz MR, 2008. Assesing A.L. 288-1 femur length using computer-aided three-dimensional reconstruction. J Hum Evol 55: 665-671.

Vialet A, Guipert G, Jianing H, Xiaobo F, Zune L, Youping W, Iantyaum L, Lumley MA, Lumley H, 2010. Homo erectus from the Yunxian and Nakin Chinese sites: Anthropological insights using 3D virtual image techniques. CR Palevol 9: 331-339.

Zollikofer CPE, Ponce de León MS, Lieberman DE, Guy F, Pilbeam D, Likius A, Mackaye HT, Vignaud P, Brunet : 2005. Virtual cranial reconstruction of Sahelanthropus tchadensis. Nature 434: 755-759. 
Figure captions

Figure 1. Lateral view of ATD6-96.

Figure 2. Digital reconstruction of ATD6-96 using the mean values obtained in the modern human sample: ES-ES=19.7 $\mathrm{mm}$ and IS-IS= $16.5 \mathrm{~mm}$. The original is the left side (yellow). Note that for technical limitations a value of 20.05 instead of 19.7 was obtained in the reconstruction. See text for further details.

Figure 3. Digital reconstruction of ATD6-96 using the mean values obtained in the Mauer specimen human sample: IS-IS=18.9 mm; ES-ES: 22.00; Infradent-M3: 63.69mm; M3(buccal)-M3(buccal): 75.90mm; L7: 53.01mm and L11: 98.28 (see text for further details). The original is the left side (red).

Figure 4. Index of the alveolar arcade measured on different species and specimens. A vertical dashed grey line is marked in the value of 100 , which means that both lineal measures used to obtain the index are equal. All the species/specimen raw data, including their sample sizes, were obtained from Rosas and Bermúdez de Castro (1998). ATD6-96 is represented by the values of the indexes obtained by reconstructing the mandible using eighteen different models. See text for further details. Note that none of the indexes of Homo antecessor falls beyond 100. A. afa: Australopithecus afarensis; Bar: Baringo; D211: Dmanisi mandible; H. hab: Homo habilis; H. erg: Homo ergaster; Chi: China; Tig: Tighenif; ATD6-96: Homo antecessor mandible; SH : Sima de los Huesos; H. hei: Homo heidelbergensis; $H$. nea:Homo neanderthalensis; H.sap: Homo sapiens. See Table 3 of Rosas and Bermúdez de Castro (1988) to check the specimens included in each sample.

Figure 5. Total mandibular length (L11) plotted against the total length of the alveolar arcade (L7). Gabounia et al. (2002) obtained these measurements for the sample of fossil specimens included in this figure. The average of L7 for the eighteen reconstructions of ATD6-96 was also plotted against the average of L11 obtained in 
these reconstructions. Minimum and maximum ranges for L7 and L11 are represented as vertical and horizontal dashed lines. Note the small size of ATD6-96 in relation to other fossil specimens.

Figure 1

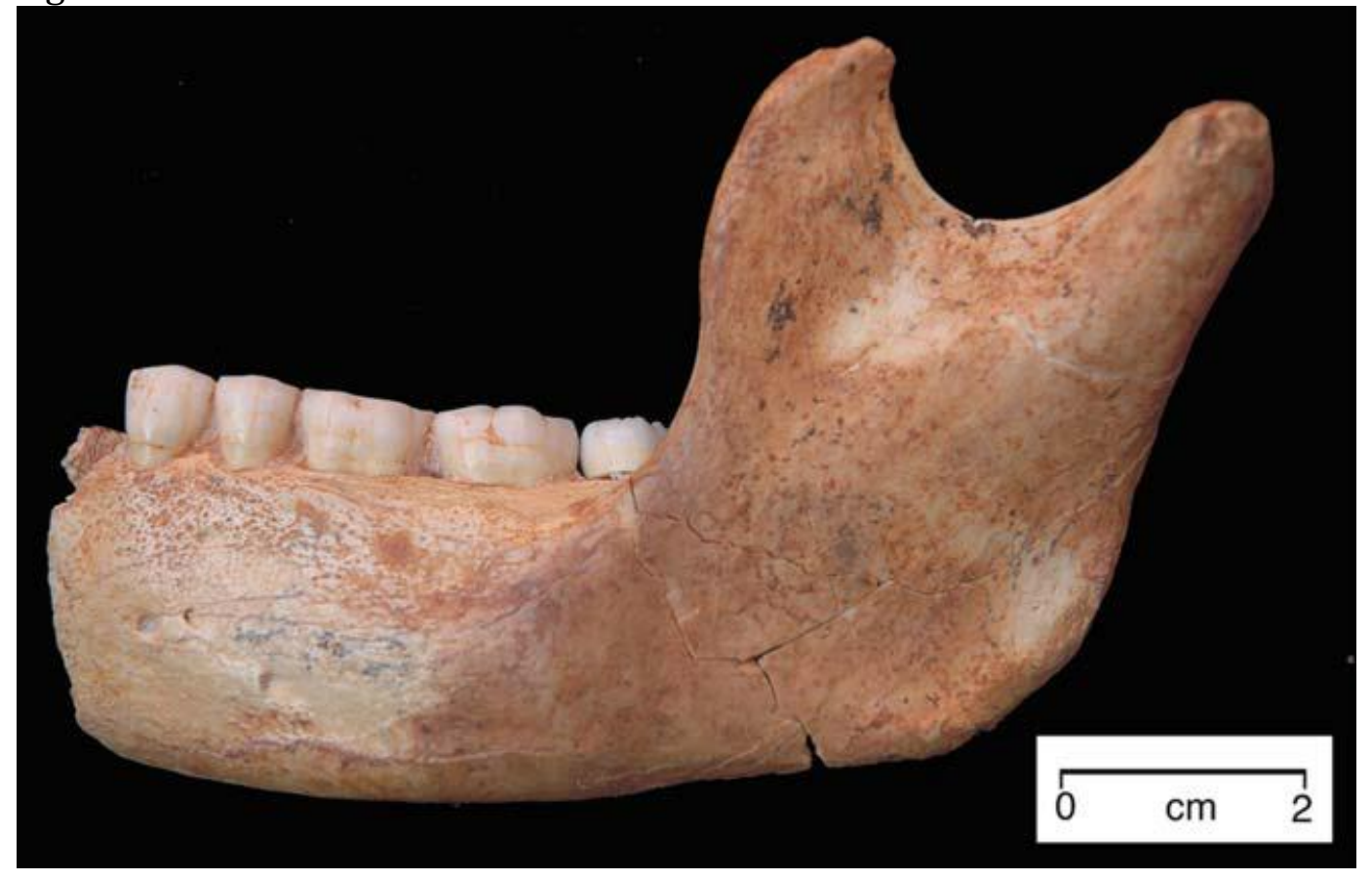

Figure 2 


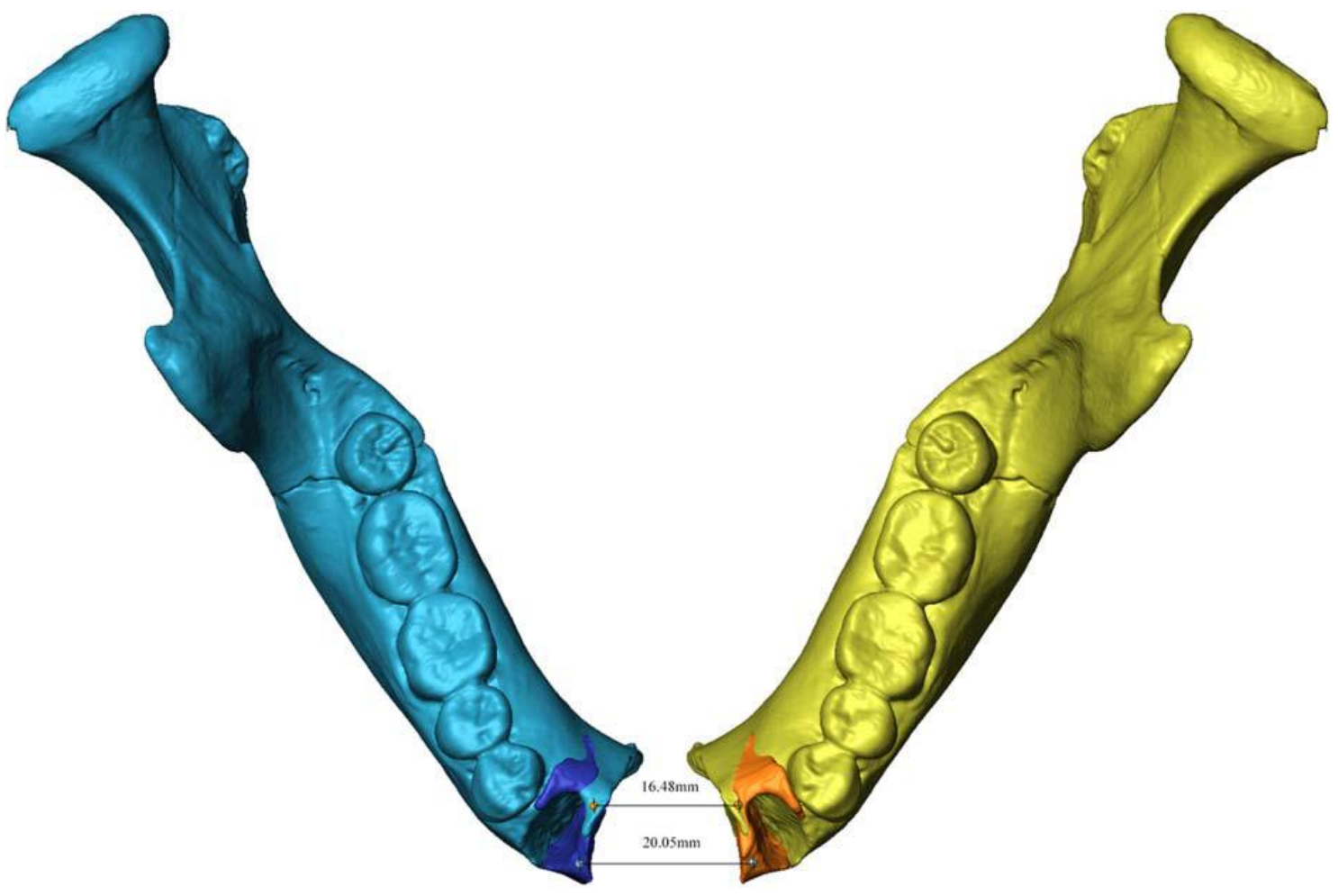

Figure 3

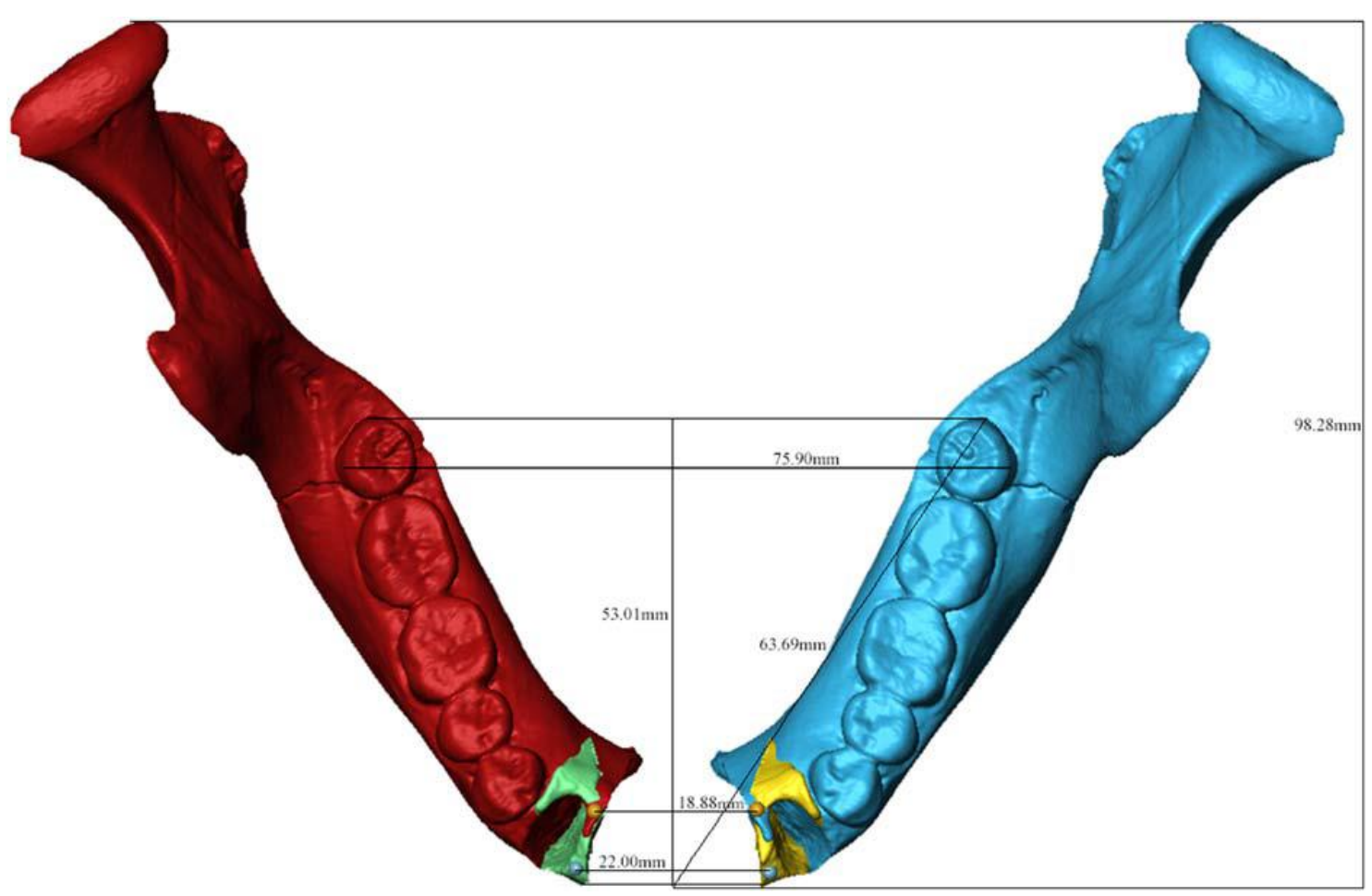


Figure 4

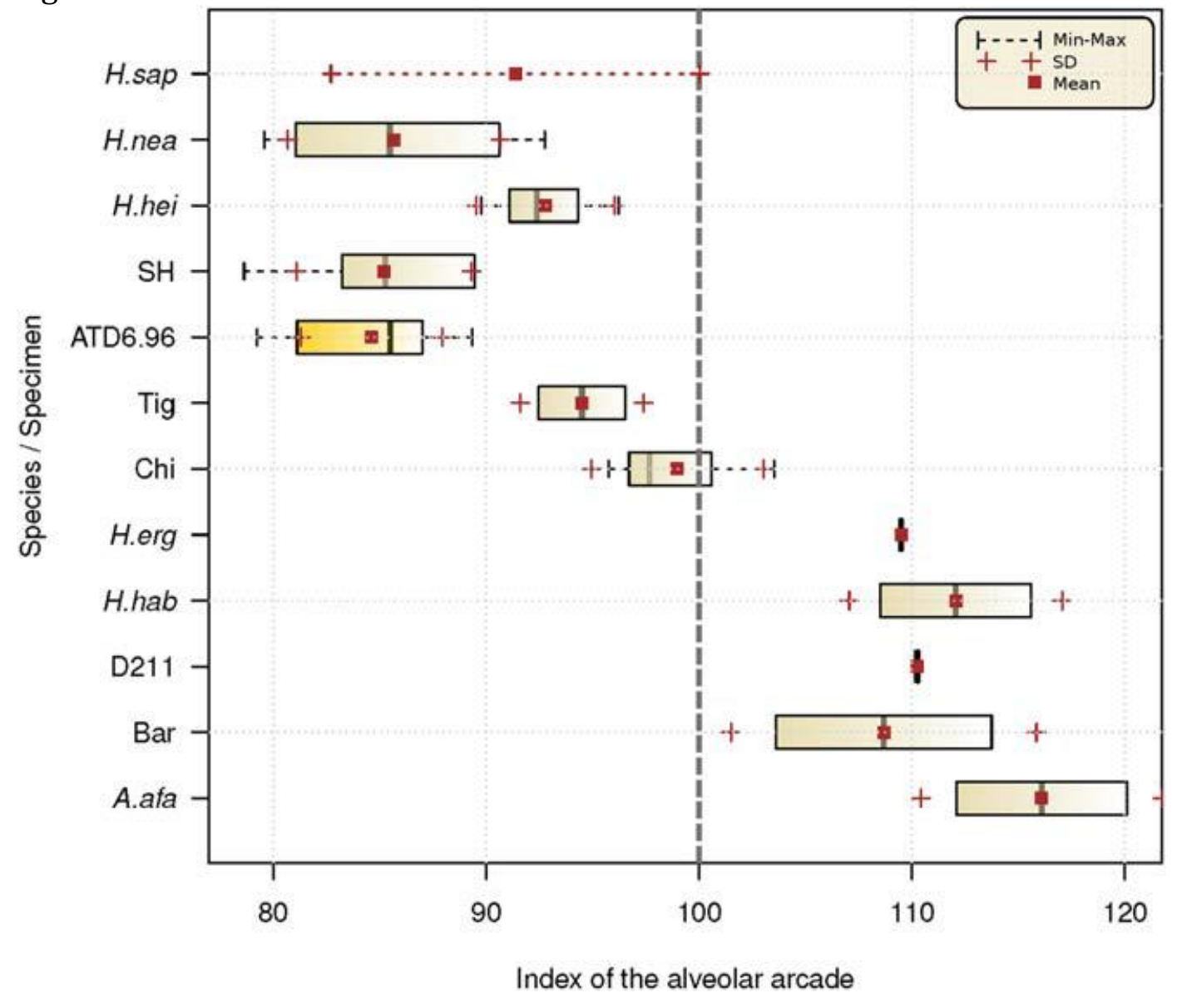

Figure 5 


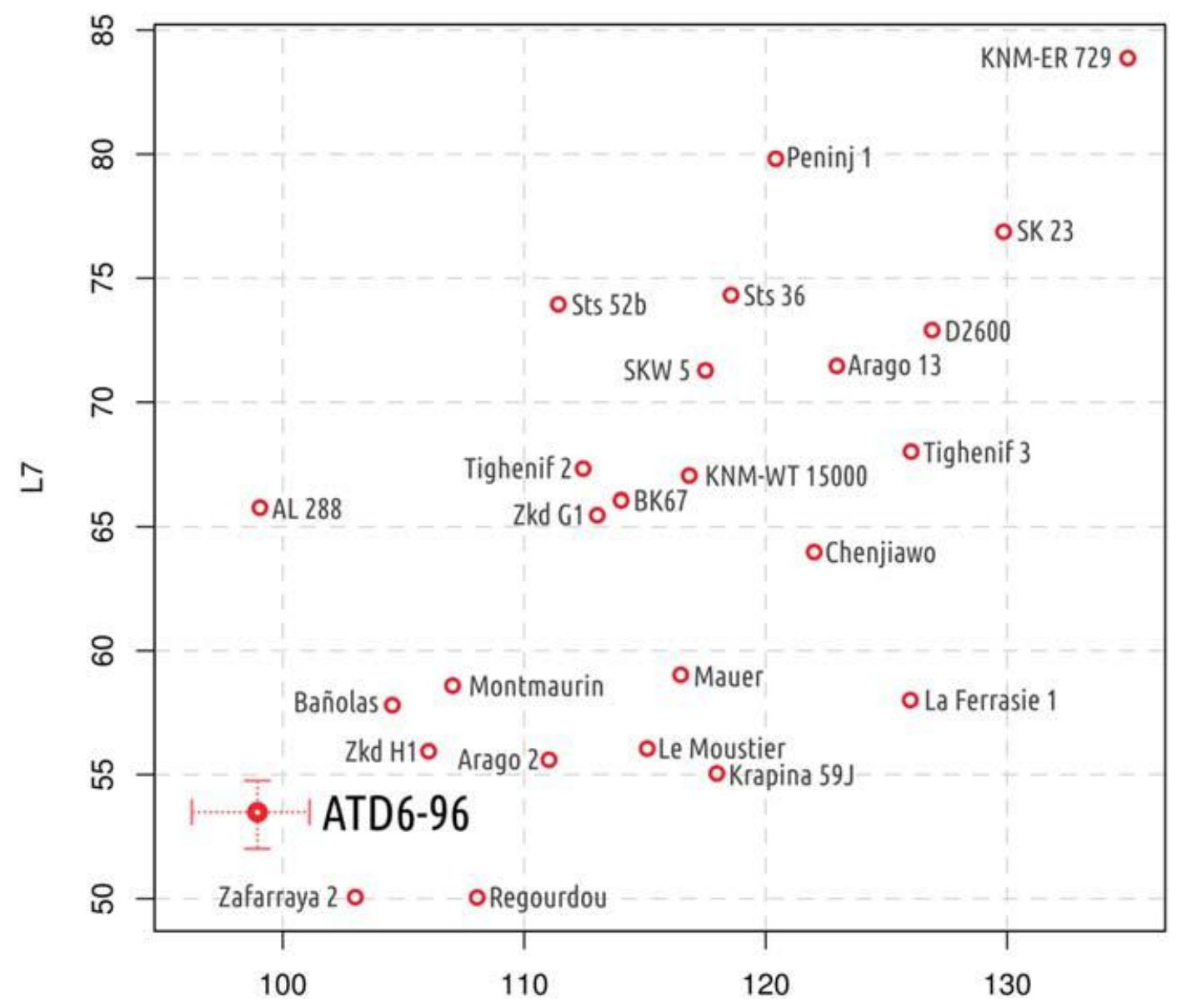

L11

Table 1. Descriptive statistics for the IS-IS* and ES-ES* measurements of the modern human sample form the San Jose cemetery.

\begin{tabular}{lcccc}
\hline & $\mathrm{N}$ & $\mathrm{X}$ & $\mathrm{S} . \mathrm{D}$. & Range \\
\hline IS-IS & 30 & 16.48 & 1.20 & $14.27-19.84$ \\
ES-ES & 30 & 19.73 & 1.49 & $17.43-22.86$ \\
IS-IS/ES-ES & 30 & 83.66 & 4.54 & $75.80-92.50$ \\
\hline
\end{tabular}

* IS-IS and ES-ES: see text for a definition of these measurements

Table 2. Value for the IS-IS and ES-ES measurements in some Homo specimens.

\begin{tabular}{lccc}
\hline & IS-IS & ES-ES & IS-IS/ES-ES \\
\hline D 211 & 17.38 & 21.54 & 80.68
\end{tabular}




\begin{tabular}{llll} 
D 2735 & 20.44 & 22.28 & 91.74 \\
KNM-ER 820 & 18.07 & 22.55 & 80.13 \\
KNM-WT 15000 & 20.86 & 24.37 & 85.59 \\
Tighenif 2 & 20.74 & 24.76 & 83.76 \\
Tighenif 3 & 21.49 & 25.9 & 82.97 \\
Mauer & 18.88 & 22.00 & 85.80 \\
Arago 2 & 20.87 & 26.20 & 79.65 \\
Atapuerca-SH IV1 & 16.4 & 20.76 & 78.99 \\
Atapuerca-SH XII & 20.19 & 23.34 & 86.50 \\
Atapuerca-SH XV & 18.43 & 23.43 & 78.65 \\
Atapuerca-SH XIX & 19.70 & 24.25 & 81.23 \\
Atapuerca-SH XXII & 17.29 & 21.20 & 81.55 \\
Atapuerca-SH XXVIII & 19.15 & 23.75 & 80.63 \\
Zafarraya & 17.80 & 20.25 & 87.90 \\
\hline 1.Atapu, Sima
\end{tabular}

1. Atapuerca, Sima de los Huesos site. In Roman numbers: individual.

Table 3. Values of the bi-molar M3-M3 distance (width) and infradental-M3 (length), and length/width index obtained using different reconstructions from a modern human sample and some hominins.

\begin{tabular}{lccc}
\hline & $\begin{array}{l}\text { bi-molar M3-M3 } \\
\text { distance }\end{array}$ & Infradental-M3 & $\begin{array}{l}\text { Length/Width } \\
\text { Index }\end{array}$ \\
\hline $\begin{array}{l}\text { Modern sample } \\
\text { (mean value) }\end{array}$ & 73.6 & 62.5 & 84.9 \\
Modern sample & 73.6 & 62.6 & 85.1 \\
95\% lower IS-IS & & & \\
23 & & &
\end{tabular}




\begin{tabular}{llll} 
Modern sample & & & \\
95\% upper IS-IS & 73.0 & 62.9 & 86.1 \\
D 211 & 74.0 & 63.5 & 81.1 \\
D 2735 & 78.3 & 63.5 & 85.5 \\
KNM-ER 820 & 74.4 & 63.6 & 79.5 \\
KNM-WT 15000 & 80.4 & 63.9 & 80.1 \\
Tighenif 2 & 80.2 & 64.2 & 79.2 \\
Tighenif 3 & 81.2 & 64.3 & 83.9 \\
Mauer & 75.9 & 63.7 & 79.5 \\
Arago 2 & 80.4 & 63.9 & 88.9 \\
Atapuerca-SH IV1 & 71.1 & 63.2 & 85.5 \\
Atapuerca-SH XII & 74.8 & 64.0 & 87.7 \\
Atapuerca-SH XV & 72.4 & 63.5 & 87.1 \\
Atapuerca-SH XIX & 73.5 & 64.0 & 89.3 \\
Atapuerca-SH XXII & 71.1 & 63.5 & 88.0 \\
Atapuerca-SH XXVIII & 72.7 & 64.0 & 85.1 \\
Zafarraya & 74.7 & 63.5 & \\
\hline 1. Atapuerca, Sima de los Huesos site. In Roman numbers: individual.
\end{tabular}

Table 4. Measurements of the mandible in a large hominin sample ${ }^{1}$

\begin{tabular}{llll}
\hline Specimen & $\begin{array}{l}\text { Total length } \\
\text { (L11) }\end{array}$ & $\begin{array}{l}\text { Length of the alveolar } \\
\text { arcade (L7) }\end{array}$ & L7/L11 X 100 \\
\hline
\end{tabular}

ATD6-96

(mean value $)^{2}$

98.9
53.5

54.1 


\begin{tabular}{|c|c|c|c|}
\hline AL 288 & 99.0 & 65.8 & 66.5 \\
\hline Sts $52 \mathrm{~b}$ & 111.4 & 73.9 & 66.3 \\
\hline Sts 36 & 118.6 & 74.3 & 62.6 \\
\hline SK 23 & 129.9 & 77.9 & 59.9 \\
\hline SKW5 & 117.5 & 71.3 & 60.7 \\
\hline Peninj & 120.4 & 79.8 & 66.3 \\
\hline KNM-ER 729 & 135.0 & 83.9 & 62.1 \\
\hline KNM-WT 15000 & 116.8 & 67.0 & 57.4 \\
\hline BK 67 & 114.0 & 66.1 & 58.0 \\
\hline D 2600 & 126.9 & 72.9 & 57.4 \\
\hline Tighenif 2 & 112.4 & 67.3 & 59.9 \\
\hline Tighenif 3 & 126.0 & 68.0 & 53.9 \\
\hline Chenjiawo & 122.0 & 64.0 & 52.4 \\
\hline Zhoukoudian H1 & 106.0 & 56.0 & 52.8 \\
\hline Zhoukoudian G1 & 113.0 & 65.5 & 57.9 \\
\hline Mauer & 116.5 & 59.0 & 50.6 \\
\hline Arago 2 & 111.0 & 55.6 & 50.1 \\
\hline Arago 13 & 122.9 & 71.5 & 58.2 \\
\hline Montmaurin & 107.0 & 58.6 & 54.7 \\
\hline Zafarraya 2 & 103.0 & 50.1 & 48.6 \\
\hline Le Moustier & 115.1 & 56.1 & 48.7 \\
\hline Krapina 59J & 118.0 & 55.0 & 46.6 \\
\hline La Ferrassie & 126,0 & 58.1 & 46.1 \\
\hline
\end{tabular}


$\begin{array}{llll}\text { Regourdou } & 108.0 & 50.1 & 46.4\end{array}$

$\begin{array}{llll}\text { Bañolas } & 104.5 & 57.8 & 55.3\end{array}$

1. Data obtained from Gabounia et al. (2002)

2. These values represent the average measurements of L7 and L11 obtained from the eighteen reconstructions made in this research. 